\title{
1l Macrothink
}

\section{Adjustment Mechanisms of New Workers in Industrial Organisations: Implications for Nigerian Workers}

\author{
Olusheyi A. Shadare \\ Department of Industrial Relations and Personnel Management, University of Lagos, Akoka \\ Yaba, Lagos, Nigeria \\ Email: bolawolemsa@gmail.com \\ GSM: +2348033049507
}

Samuel Emeka Mbah.

Department of Ind ustrial Relations and Personnel Management, University of Lagos,

Akoka, Yaba, Lagos, Nigeria

GSM: +2347037634818 \& +2347087566201

Email: mbasam2011@yahoo.com

Accepted: August 11, 2013 Published: Sep 04, 2013

Doi:10.5296/ijhrs.v3i3.4219 URL: http://dx.doi.org/10.5296/ijhrs.v3i3.4219

\begin{abstract}
This paper adopted qualitative and theoretical method of analysis to describe adjustment mechanisms of new workers in industrial organisations in Nigeria. The purpose was to take a close theoretical analysis of different types and processes of new workers adjustments. The paper highlighted different typologies and processes of adjustments such as personal adjustment, labour-market adjustment, and adjustment to new structures, policies and new behaviours in work organisations. Empirical literature revealed that new workers adjust to work environment, to new labour policies such as pay and performance management, regular hours of work, work pressure, to new organisational structure as well as of collective bargaining outcome among others. The paper highlights reasons why work adjustments occur in organisations to include: Pay status, affiliation, ego, power, emotion and curiosity and these factors motivate new workers to increase commitment. The paper then concludes that practitioners and managers ultimately should seek to design adjustment strategies that take individual newcomer characteristics into consideration and encourage proactive behaviour such as information seeking that help facilitate the development of role clarity, self - efficacy, social acceptance and knowled ge of organisational culture.
\end{abstract}

Key Words: Adjustment mechanisms, New workers, Industrial organisations, Nigeria.

\section{Introduction}

Why do people work? Primarily, People work to get pay so that they can take care of all their 
economic, physiological, social, political, etc needs and to feel self actualized or fulfilled both within and outside work organisation (Maslow, 1954). If people must work for whatever reason, and if work means they must join an organisation, they do have a choice as to which organisation that is most likely to fulfill their needs (Allen, 1971). Industrial or work organisations are complex social units that are specially designed to provide goods and services to their customers and their environment through the concerted efforts of their members who are workers in the organisations. There are exactly no two organisations alike, for they differ either in size, in goods or services they render, in technology they employ or principles they apply (Tannenbeum 1966). The same way individuals are unique and make choice of a particular organisation that is most likely to fulfill their needs. The organisation also has a choice; it can accept or refuse an individual's offer to join. The successful organisation chooses workers whom it believes will serve its objectives. To the employees, however, the organisation's goals are secondary. Their personal goals, money, power, and self-fulfillment are their primary goals. Therefore, work organisations must make their employees feel that the way to achieve their personal, primary goals is through achieving the organisation's goals. In other words, they have to subordinate their interests to the interests of the organisations (Fayol, 1916).

At one time or the other, every worker is a new comer. As a new comer, organisational socialisation is very important. Important because socialisation within the work environment will enhance necessary adjustments and integration. The newcomer is indeed new and confronted with challenges of new environment and new behaviours such as building relationships, seeking information and feedback, clarifying expectations, learning organisational values and norms and gaining social acceptance (Bauer and Erdogan, 2011). Organisational socialisation is a mechanisim through which new employees acquire the necessary knowledge, skills and behaviours to become effective organisational members and insiders (Bauer and Erdogan, 2011). Organisational socialisation is also known as onboarding or induction which means orientation ceremonies or activities aimed at introducing new workers to their new jobs and this process precedes work adjustments (Saari and Judge, 2004). Induction of employees has gone beyond mere ceremonies in the contemporary times. Organisations adopt such tactics as formal meetings, lectures, videos, printed materials computer- based orientations among others to introduce new workers to their new jobs.

The choice of where and place to work is not a matter of chance rather it is one that is predetermined, planned and accomplished. A new comer once onboard is confronted with new behaviours which demand for systematic adjustments to the task environment which necessitates the achievement of organisation objectives. Watson (1987:27) argues that “........ although employees tend as far as possible to select employment in keeping with their priorities in what they want from work, they nevertheless make important accommodation and adjustments once in work as their experience are influenced by much workplace factors such as work processes, pay levels and power structures". Work processes, pay levels and power structures are determined by management. Whenever an individual takes up employment the individual inevitably surrenders a certain amount of autonomy to 
management dictates (Watson, 1987). This gives rise to a type of psychological contract between the worker and management in which the set of mutually agreed expectations in terms of rewards and effort at work are made (Bratton, \& Jeffrey, 1999). In keeping with this contract, the new comer makes every effort to make adjustments. These adjustments are responses to new environment, personal, structural or job demands and any other form of adjustments pertaining to both the individual newcomer and the organisation at large. This paper therefore takes a close theoretical analysis of different types and processes of new workers adjustments with a focus on Nigerian workers. In order to achieve this purpose, the paper is structured into the following sections:

\section{Lite rature Review and Conceptual frame work}

Fox (1971) states that the work organisation is a social system. A social system is created by

People who come together to achieve common goals. Their activities are governed by conventions of social behaviour. This form of social system is not static; it is dynamic and it changes with changing circumstances(Laird, 1975). Changes that occur within an organisation must reflect harmonious relationships among workers across all levels of hierarchy.

The Webster reference dictionary, defined the word 'adjustment' as adaptation to a need, to satisfy specific condition and the word mechanism to mean procedures by which a particular effect is produced or a purpose is accomplished. Saks and Ashforth (1996), defines the concept of adjustment as being originally borrowed from biological term 'adaptation' which refers to effort by a specie to adjust to changes in its environment. We all respond to our environment and to the changes that occur within it. Adjustment mechanism therefore is a conscious or unconscious mental process which motivates emotional and behavioural responses (Tannenbeum, 1966). Jones (1986) maintains that when a person first enters a work organisation, the degree of correspondence may not be high. The person has to develop skills and become acquainted with the environment, while the work organisation has to become acquainted with the new worker. Since both the individual and the work environment constantly change, there is a continuous process by which the individual seeks to maintain correspondence and compatibility. Jones (1986) called this process "work adjustment". Research has demonstrated that well adjusted new worker is likely to enjoy high job satisfaction, better performance, greater organisational commitment, reduction in stress and intent to quit (Ashford and Black, 1996; Kammeyer-Mueller and Wanberg, 2003; and Fisher, 1985).

Adjustment is a concept dominated by psychology literature, it means adaptation to work and individual needs. It is a dynamic process. How well individuals adjust depends on certain factors, namely, personal characteristics such as skills, attitudes, physical conditions and the nature of the situations or conditions that may confront the individual, such as changes in the existing situation or condition within the work organisation. In which ever way, extremely rapid rate of changes in modern organisations and the world in general demands that 
adjustment must take place all the time. There are different conceptualised forms of work adjustments and they take three basic forms as follows:

a Personal adjustment,

b Labour-market adjustment,

c Adjustment to new structures and policies.

a. Personal Adjustment: Personal adjustment means the psychological processes through which people manage or cope with the demands and changes of every day work life in the organisation or industry. The fact that an organisation has achieved social balance does not necessarily mean that people in it are adjusted (Weiss 1964). As social balance is important to the system, personal adjustment reflects the individual's state of harmony with the system. Just as stated, adjustment is not a one-time thing, achieved at a particular time, say after being on the job for a few week's and learning the job. It is a continuing process. An individual is constantly seeking to maintain adjustment (Crant, 2000).

If a person has difficulty adjusting or adjusts in a way that is not approved of by society, that person is said to be maladjusted. All people have difficulty adjusting at certain times, but when the person consistently fails to adjust then, the problem becomes one of maladjustment. When there is maladjustment, there are many problems. In the work organisation, maladjustment takes the form of worker turnover, labour agitation, insubordination, absenteeism, tardiness and even crime in the form of theft (Laird, 1975). If a person begins a new job displaying a habit of tardiness, this maladjustment may lead to dismissal or resignation very soon. For an individual to achieve personal adjustment in a social system, two types of actions must occur simultaneously. One type is socialising, which is the process by which the organisation strives to make the individual its agent to achieve organisational goals. The other action is personalising, which is the process by which the individual strives to make the organisation his or her agent for the achievement of personal goals. This simply implies the integration of expectations of organisations with those of the individual workers within the organisation and this promises a harmonious relationship.

When people join organisations, they have clearly understood, spoken or written contract covering wages and working conditions. But people also expect something more. These expectations are not written down and may not even be spoken. Some social Scientifics refer to these expectations as the Unwritten Psychological Contract (Laid, 1975). This contract exists only in the worker's mind, but it covers conditions employees expect to be met in return for their involvement with the system. For giving a certain amount of work and loyalty workers expect more than a pay cheque. They seek security, treatment as human beings, rewarding relationships with other people and support in fulfilling their personal goals (Laird, 1975). If the organisation honours only the economic contract, wages, holidays, vacations, and working conditions, it may or not be written but is clearly understood, employees will lose interest and eventually leave to join work organisations that are more rewarding to them. Another type of adjustment is the concept of labour market adjustment.

\section{b. Concept of labour- market adjustment}


Atkinson (1984) was accredited with the most popular distinction of labour market flexibility. This refers to the flexible use of form of labour and overtime as a means of adjusting to short term additional demand in work organisations. To this, various typologies of labour flexibility have been advanced. Rimmer and Zappala (1988) developed the five most straight forward typologies of labour flexibility to include:

i. External numerical flexibility, which concerns the ability of firms to adjust the level of labour input by hiring new labour, for instance, non standard forms of employment for example Casual, temporary, contract, agency labour etc.

ii. Internal numerical flexibility or temporal flexibility, where employers make use of more flexible overtime, shift rosters including night shifts, week end shifts and other working time arrangements as means of adjustment to short term additional demand (Fagan, Hegewisch and Pillinger, 2006).

iii. The functional flexibility or organizational flexibility which concerns the capacity of employers to move labour to different functions or tasks within the firm. It relates to organisation of operations or management and training workers. This can be achieved by outsourcing activities and was noted to have motivated a successful restructuring programme in Australia and New Zealand (Wallace, 2001). Job rotation is a label given to many functional flexibility schemes (Chung 2006).

iv. Wage or financial flexibility relate to means of labour adjustment where pay rates are more closely aligned with product and labour market conditions.

v. The final, is procedural flexibility which provides the machinery for consultation and negotiation above all other cited types of flexibility. There are yet other types of flexibility that can be used to enhance adaptability.

The one that is worth mentioning is location flexibility or flexibility of place which entails employees working outside of normal work place such as home based work, outworkers or tele- workers. This can also cover workers who are relocated to other offices within the establishment, flexibility for workers. As Gerson and Jacobs (2004) agree, "flexibility and autonomy are only useful if workers feel able to use them"

In these five typologies, Rimmer and Zappala (1988) came to the conclusion and scientifically proved that overtime is the most internal flexible means of labour-market adjustment to short term additional employee demand in work organisations.

\section{c. Adjustment to new structures and policies}

New workers adjust to new structures and policies. For instance, employees and organisations make adjustments when new technologies or policies or restructuring take place. According to Helpman and Antonio (1998) the arrival of a new technology produces two types of effects, a switch effect and entry effect. Aggregate output is determined by their interplay. David, Katz and Allan (1998) state that the switch effect occurs when workers who have experience in the old sector switch or adjust to the new. A loss of output may occur under these circumstances because experience accumulated with the old technology is not transferable to the new sector. Now the switch effect is positive because the productivity gains embedded in the new technology outweigh the loss of human capital in the old sector. 
The switch effect can also be negative however. Output falls for example, when the productivity of inexperienced workers is higher with the old technology. In this case young workers may voluntarily switch - taking a wage cut in the process in expectation of high wages in the future, when they will have more experience with the new technology. Until enough experience has been gained in the new sector, the switch can produce a recession causing some to quit or face retrenchment or downsizing. The same is applicable when new policies or restructuring exercises are introduced in organisations. Workers make several forms of adjustments and sacrifices. Those who are considered unfit are retrenched while the most fits remain. The big question is why do workers make adjustments? In other words what are the motives relevant to adjustments in organisations.

\section{1 Motives relevant to work adjustment}

Tannenbaum, (1966) gave a highlight on motives relevant to the adjustment of organisation members as follows: -

$\square \square$ Need for affiliation: - That man seeks the company of others and for reasons of social contact, man desires to be in a state of continuous friendship, need for Union and or companionship. Tannenbaum (1966) referred to this psychological instinct as 'gorgeousness'. Abraham maslow (1954) in his hierarchy of need theory acknowledges affiliation as one of the workers basic needs that has implication for their adjustments. It is a motivator which may encourage performance, hence, makes adjustment possible.

\section{$\square \square$ Ego motives:}

This refers to a person's self-identity. Individuals are generally motivated to achieve and maintain a good self-concept. They want to think well of themselves to have in Maslow's terms, self-respect or self-esteem. Satisfaction of the need for esteem is accompanied according to Maslow by feelings of adequacy, well being and confidence. Skills, talents and abilities are often associated with an individual's self-identity. They are not in themselves sources of motivation but represent potentials or capabilities that individuals want to fulfill. The terms self-actualization and self-fulfillment are sometimes used to describe this need in people to employ their skills and realize whatever their potentialities may be.

\section{$\square \square$ Power motives:}

Individuals have feelings about power, about controlling others and being controlled by others. Power in social situations, is often considered a mark of status or of success. It may be sought to satisfy these goals.

\section{$\square \square$ Curiosity:-}

Man's curiosity leads him to seek, explore, to order, investigate or to manipulate many aspects of his environment. Curiosity motive is most likely to find opportunity for expression where the environment of the individual is complex, strange, novel, varied or surprising. This in effect makes the man's needs and motives endless and to remain always in search.

\section{$\square \square$ Security:}

By security, it means a state in which most of the important needs of a person can be satisfied and in which the individual is reasonably assured of their continued satisfaction. Insecurity implies apprehension or anxiety about the maintenance of these satisfactions and may be 
associated with economic, social or psychological factors. Persons who fear the loss of a job or steady income, or are in doubt about their ability to meet their bills, to achieve their aspirations or to maintain friendships or other relationships that are important to them are likely to suffer a sense of insecurity. Insecurity may be situational for example; it may result from a failure caused by adverse circumstances. Or it may be a more permanent function of personality some people is insecure even though they are successful by all outward standards. Insecurity is a distressing and sometimes debilitating emotion that can cause maladjustment (Tannenbaum, 1966).

\section{Emotion motives:}

Emotions play important role in life. Emotions are outward expression of inner feelings which are aroused by one's behaviour or that of others. Emotions can be classified into two; pleasant emotions include joy, love, affection, happiness, pleasure, humour and laughter. They facilitate growth and development and bring about good mental health and adjustment in the individual throughout his work life. Unpleasant emotions include fear, anger anxiety, sorrow jealousy, guilt, and hatred. These sometimes impede or inhibit growth and development and could result in maladjustment through out individuals work life.

In all, since change is constant and as long as individuals remain part of the work organisation which is also dynamic and given that the environment is also dynamic, the individual must constantly respond to change. No matter how, where and when such a change arises, in work organisation; the worker must continuously adjust to suit whatever change that occurs. This is important to maintain continuity and organisational balance.

\section{The role of the organisation on employee adjustment}

Organisations monitor how well their newcomers or hires are adjusting to their new roles, responsibilities, peers, supervisors and the organisation at large. Saari and Judge (2004) noted that role clarity, self-efficacy, social acceptance and knowledge of organisational culture are particularly good indicators of well- adjusted new employees who have benefitted from an effective organisational socialisation.

\section{i. Role clarity}

This describes the extent to which the new employee understands his or her job responsibilities and organizational role. This is usually a function of good and effective socialization tactics. A poor tactic will result to producing employees who are unsure of their exact roles and responsibilities while the strong socialisation will produce employees who know what their job tasks and organisational roles are. Increasing role clarity is very important for proper adjustment.

\section{ii. Self-efficacy}

Self-efficacy is the ability of new worker to feel successfully accomplishing the job task assigned to him or her. Employees who feel strong believing they can get the job done would fare better than those who feel otherwise. Studies confirmed that job satisfaction, organisational commitment and turnover are all correlated with feelings of self-efficacy (Kammeyer-Mueller and Wanberg, 2003). 
iii. Social acceptance

This gives the new employees the support needed to be successful that is the feeling of "fitting in" can do a lot in work environment and this can increase or reduce commitment and even turnover (Kammeyer-Mueller and Wanberg, 2003).

\section{iv. Knowledge of organisational culture}

According to (Klein and Weaver, 2000) knowledge of organisational culture refers to how well a new employee understands a company's values, goals, roles, norms and overall organisational environment. The knowledge of one's organisational culture is important for newcomer looking to adapt to a new company. This allows for social acceptance and aids in completing work tasks in a way that meets company standards. Overall knowledge of organisational culture has been linked to increased satisfaction and commitment as well as decreased turnover (Klein and Weaver, 2000).

\section{Implications for Nigerian workers}

Some of the most common typical examples of adjustment processes of new workers in ind ustrial organisations in Nigeria are:

i. Workers adjustment to any new policy, practice or changing conditions in the organisation if they are allowed to involve in decision - making. When there is a resolution they are compelled to adjust to them when and where necessary.

ii.Mental adjustment is required on both labour and management to be able to ensure a successful collective bargaining process (Faulks, 2004). Regular individual or personal adjustment is required for its success.

iii. In terms of pay and performance, workers adjustment to performance is a function of reward system of any organisation. Every worker is motivated by the level of his or her pay. If the pay is high, the worker adjusts to high performance, if low pay the worker responds to low performance also, this type of reward system is based on productivity and some organisations base their reward system on performance level or productivity and workers adjust to it accordingly.

iv. Employees adjust to new labour policies and practices that are outcome of labour negotiations and consultations with management. For instance, workers are expected to adjust to new hours of work, new job structure, resumption and closing time, break time, leave period, overtime etc.

Employees are expected to adjust to regular sectional meetings and briefings that go on in most organisations. Briefing is towards fashioning out more strategies on how to carry out day- to- day activities of individuals in the organisations and workers adjustments to briefing outcome.

\subsection{Implications for policy and practice}

Employees' job attitudes are particularly important from an organisation's perspective. This is because employee job attitude has a link to employee engagement and performance on the job. Employee engagement attitudes such as satisfaction with one's job and organisational commitment or loyalty have important implications for employees' work performance and 
intention to stay with or quit an organisation. This translates to strong financial gains for organisations as research has shown that individuals who are highly satisfied with their jobs and who exhibit high organisational commitment are likely to perform better and remain in an organisation whereas individuals who have developed negative attitudes are highly dissatisfied and unattached to their jobs are characterized by low performance and high turnover rates ( Saari and Judge, 2004 and Ryan, Schmit and Johnson,1996). Since, attitudinal formations begin from the initial point of contact with organisation, managers and practitioners would be wise to take advantage of positive attitudinal development during adjustment periods in order to ensure a strong, productive and dedicated workforce.

\subsection{Research Methodology}

This paper adopted a qualitative approach predicated on secondary or library sources of data collection method. The secondary or library sources of data collection included textbooks, journal articles, internet source and so forth.

\section{Summary}

This paper examined the adjustment mechanisms of new workers in industrial organisation in Nigerian. It established that individuals in organisation work and make choice of the organisation that is most likely to fulfill their needs. The paper highlighted three basic typologies of adjustment mechanisms as personal adjustment, labour - market adjustment and adjustments to new structures and policies. Certain motives relevant to individual adjustments such as need for affiliation, ego, and power, Curiosity, security emotion etc in industrial organisations were also highlighted. The paper also identified the following as adjustment processes, adjustment to new work environment, to new labour policies such as pay and performance management, regular hours of work that is, adjustment to work pressure, adjustment to new organisational structure and policies such as of collective bargaining outcome among others. Workers require to properly adjusting to any of this to be productive and satisfactory members of industrial organisation.

\subsection{Concluding remarks}

It is certain that entering the right job or career is a problem most people face when entering the work organisation and as such correspondence between new individuals and environment pose difficult relationship. This therefore makes it imperative for the individuals to continuously seek to maintain correspondence. Work adjustment is most significant for new workers as it provides lasting work experiences. Therefore, practitioners and managers ultimately should seek to design adjustment strategies that take individual newcomer characteristics into consideration and encourages proactive behaviours, such as information seeking, that help facilitate the development of role clarity, self - efficacy, social acceptance and knowled ge of organisational culture. All of this will ensure better commitment decrease turnover and intent to stay. 


\section{REFERENCES}

Allen, V.L. (1971). The Sociology of industrial relations: Studies in method. London: Longman group Ltd.

Ashford, S. J., \& Black, J. S. (1996). Proactivity during organisational entry: The role of desire for control. Journal of Applied psychology, 81, 199-214.

Atkinson, J. (1984). flexibility, uncertainty and manpower management. IMS Report No. 89, Institute of manpower studies, Brighton.

Bauer, T. N. \& Erdogan, B. (2011). Organisational adjustment: The effective adjustment of new employees. In S. Zedeck (Ed.), APA handbook of ind ustrial and organizational psychology, Vol. 3, Maintaining, expanding and contracting the organisation, APA Handbooks in Psychology pp 51-64. Washington DC,US: American Psychological Association.

Bratton, J. \& Jeffrey, G. (1999). Human resource management: Theory and practice, London: Macmillan Press Ltd.

Chung, H. (2006). Labour market flexibility for employers or employees? A multidimensional study of labour market flexibility across European welfare states, paper presented at the 2006 Annual ESPAnet Conference, Shaping European Systems of Work and Welfare, 7-9september 2006, Bremen. Paper link.

Crant, J. A. (2005). Proactive behaviour in organisations. Journal of Management, 26, 274276.

David, H., Lawrence F., Katz \& Alan B. K. (1998). Computing Inequality: Have Computers Changed the Labour Market. Quarterly Journal of Economics. Vol. CXIII: 1669-1213.

Erdogan, B. \& Bauer, T. N.(2009). Perceived Over qualification and its Outcomes: The Moderating role of empowerment. Journal of Applied Psychology, 94, 557- 555.

Fagan, C., Hegewisch, A. \& Pillinger, J. (2006). Out of time: Why Britain needs a new approach to working- time flexibility.Trade union congress. London.Out of Time report link.

Faulks, O. (2004). Knowledge management or organisational competitiveness: Collective Bargaining Practices”. Journal of International Business Studies.29 (12), 245- 260.

Fayol, H. (1916). Administrative ind ustrielle et general trans lated by C. stores as general and

Fisher, C. D. (1985). Social support and adjustment to work: A longitudinal study. Journal of Management, 11, 39-53.

Fox, A. (1971). Sociology of work in industry: Themes and issues in modern sociology series. London: Collier Macmillan.

Industrial Management, London:Pitman.

Gersen, K., \& Jacobs, J. (2004). The work- home crunch. In gender and sexualities, (pp. 231240).

Helpman. E. \& Antonio, R. (1998). Adjusting to a new technology: experience and training. NBER Working Paper No. 6551.

Jones, G. R. (1986). Socialisation tactics, self- efficacy and newcomers adjustments to 
Organisations. Academy of Management Journal, 29, 262 - 279.

Kammeyer- Mueller, J. D., \& Wanberg, C. R. (2003). Unwrapping the organisational entry process: Disentangling multiple antecedents and their pathways to adjustment. Journal of Applied Psychology, 88, 771-794.

Klein, H. J., \& Weaver, N. A. (2000). The effectiveness of an organisational- level training program in the socialization of new hires. Personnel Psychology, 53, 47-66

Laird, D. (1975). Psychology: Human relations and work adjustment. USA: McGraw-Hill Inc.

Maslow, A. (1954). Motivation and personality. New York: Harper and Row.

Nigeria census statistics report, 1990.

Rimmer, C. \& Zappala, A. (1988). Labour adjustment in Australia and New Zealand. Working paper FB 325, 1-3.

Ryan, A. M., Schmit, M. J., \& Johnson, R. (1996). Attitudes and effectiveness: Examining relations at an organizational level. Personnel Psychology, 49, 855-882.

Saari, L. M. \& Judge, T. A. ( 2004). Employees attitudes and job satisfaction. Human Resource Management, 43, 395-407.

Saks, A. M. \& Ashforth B. E. (1996). Proactive adjustment and behavioural self management. Journal of vocational Behaviour, 48, $301-323$.

Tannenbaum, A.S. (1966). Social Psychology of the work organization. California, USA: Wadsworth Publishing Company, Inc

Wallace, C. (2003).Work flexibility in eight European countries: A cross- national comparison. Sociological Series 60, Institute for Advanced Studies, Vienna.

Watson, T. (1987). Sociology, work and industry. London: Longman group Ltd.

Weiss, D.A. (1964). Theory of work adjustment. Minnesota Studies in vocational Rehabilitation, N0.15. 